\title{
Violência cometida contra mulheres: necessidades humanas básicas (NHB) e os cuidados de enfermagem
}

Recebido em: 21/02/2013
Aprovado em: 16/05/2014

\author{
Vera Lucia de Azevedo Lima \\ Andrey Ferreira da Silva ${ }^{2}$ \\ Elane Borges do Rosário ${ }^{3}$
}

Resumo: O estudo tem como objetivo conhecer as necessidades humanas básicas comprometidas das mulheres vítimas de violências atendidas na Delegacia Especializada de Atendimento a Mulher (DEAM) do município de Belém - PA - Brasil. Estudo descritivo exploratório com abordagem quantitativa. As mulheres apresentaram as necessidades humanas básicas psicobiológicas e psicossociais comprometidas pela violência. A enfermagem deve identificar, diagnosticar, cuidar, notificar os casos de violência além de elaborar as ações educativas para diminuir e prevenir à violência contra a mulher para não chegar ao grau máximo, que é a morte

Descritores: Violência, Mulher, Cuidados de Enfermagem.

\section{Violence committed against women: Basic Human Needs (BHN) and nursing care}

Abstract: The study aims to meet the basic human needs of committed women victims of violence attending the Specialized Police Service Women and propose nursing care. Descriptive exploratory study with a quantitative approach. Women had the basic human needs psychobiological and psychosocial compromised by violence. Nursing must identify, diagnose, care for, and report cases develop educational activities to reduce and prevent violence against women not to reach the maximum level, which is death.

Descriptors: Violence, Women, Nursing.

Violencia contra las mujeres: necesidades humanas básicas (BHN) y la atención de enfermería

Resumen: El estudio tiene como objetivo satisfacer las necesidades humanas básicas de las mujeres víctimas de violencia cometidos que asisten a las mujeres policía especializada de servicios y proponer cuidados de enfermería. Estudio descriptivo exploratorio con abordaje cuantitativo. Las mujeres tenían las necesidades humanas básicas psicobiológicos y psicosociales comprometidos por la violencia. Enfermería debe identificar, diagnosticar, cuidar, y notificar los casos el desarrollo de actividades educativas para reducir y prevenir la violencia contra las mujeres no alcancen el nivel máximo, que es la muerte.

Descriptores: Violencia, Mujeres, Enfermería.

\section{INTRODUÇÃO}

A violência é um fenômeno que atinge mulheres de todas as classes sociais, grupos etários, em todos os países, em seu ambiente familiar e, impiedosamente, com maior hostilidade, os indivíduos mais indefesos da sociedade. Sendo a mulher a maior vítima, por conta de uma cultura patriarcal reproduzida pela sociedade, onde o homem é considerado um ser superior por sua virilidade, coragem, agressividade e principalmente por ser considerado o provedor do lar, logo a mulher é considerada um ser frágil estando sempre associado aos afazeres domésticos e a educação dos filhos ${ }^{(1),(2)}$.

O fenômeno da violência se desvela nas relações conjugais repercutindo na saúde da mulher, da família, na produtividade econômica do país relacionada à assistência a saúde e ao atendimento prestado pela justiça, apesar disso observa-se dificuldade no combate a violência por conta da mesma ser uma questão cultural e de gênero(3).

No contexto familiar a violência contra a mulher é considerada normal, transformando-se em um problema difícil de cuidar e de notificar, sendo visível a decepção da mulher durante o atendimento pela falta de capacitação dos profissionais da área da saúde ${ }^{(4)}$.

Os cuidados as mulheres vítimas de violência devem ser planejado para promover segurança, acolhimento, respeito e satisfação das necessidades individuais usando sempre instrumentos que promovam higidez e também respeito ${ }^{(5)}$.

A partir dessa perspectiva a enfermagem deve observar a vítima de uma forma holística, de modo a desenvolver ações que venham atentar para as necessidades humanas básicas comprometidas, que são estados de tensões que se manifestam a partir de um desequilíbrio homeodinâmico dos fenômenos vitais ${ }^{(6)}$, fazendo assim da violência contra a mulher uma fonte de desequilíbrio das Necessidades Humanas Básicas psicobiológicas, psicossociais e espirituais.

No Brasil tem-se observado um crescimento desordenado da violência conta a mulher, como forma de coibir a violência doméstica e de gênero, foi editada e sancionada a Lei $\mathrm{n}^{\circ}$ 11.340/2006 de 7 de agosto de 2006, denominada Maria da Penha ${ }^{(7)}$. No município de Belém, de janeiro de 2009 a dezembro de 2010, aproximadamente 22.222 mulheres em situação de violência buscaram ajuda na Delegacia da Mulher(8).

Por conta do crescente aumento do número de mulheres vítimas de violência na região norte e por ser considerada um fenômeno agravante dos problemas sociais e da saúde. A violência contra as mulheres não pode ser desconhecida dado à magnitude, transcendência e vulnerabilidade do fenômeno. Diante deste cenário, o estudo tem como objetivo conhecer as necessidades humanas básicas comprometidas das mulheres 
vítimas de violência atendida na Delegacia Especializada de Atendimento a Mulher (DEAM) do município de Belém - PA.

\section{METODOLOGIA}

Trata-se de um estudo descritivo com abordagem quantitativa. Foram entrevistadas 300 mulheres vítimas de violência atendidas na Delegacia Especializada de Atendimento à Mulher (DEAM), no período de 1 de julho a 31 de dezembro de 2011. A coleta de dados foi realizada por meio de um roteiro sistematizado com as seguintes variáveis: identificação; tipo de violência; natureza da lesão; parte do corpo atingida; meio utilizado pelo agressor; local da ocorrência da violência; grau de parentesco do causador da violência contra a mulher e identificação de suas Necessidades Humanas Básicas comprometidas com a violência. Foram incluídas na pesquisa mulheres vítimas de violência residentes em Belém com boletim de ocorrência na DEAM independente de sua faixa etária. Os dados foram agrupados, tabulados e analisados por meio da estatística descritiva.

\section{RESULTADOS E DISCUSSÃO}

Das 300 mulheres vítimas de violência que buscaram atendimento na Delegacia Especializada de Atendimento a Mulher, 23,00\% estavam na faixa etária entre 26 a 30 anos, $78,00 \%$ solteiras, $33,67 \%$ com o ensino fundamental incompleto, $29,00 \%$ do lar, $67,00 \%$ católicas, $47,00 \%$ sofreram agressão física e psicológica, $49,44 \%$ foram agredidas na cabeça/face, $44,67 \%$ foram agredidas pelo seu ex-companheiro e $76,33 \%$ dos casos ocorreram dentro do lar.

Uma pesquisa realizada no período de 2004 a 2007 revelou que as mulheres casadas ou com união estável vítimas de violência, na faixa etária entre 20 e 39 anos na fase produtiva para o trabalho e reprodutiva ${ }^{(9)}$.

Em Recife, um estudo aponta maior frequência de casos de violência em mulheres que apresentam entre zero a oito anos completos de estudos ${ }^{(10)}$, além disso, A dependência financeira é tida como uma das principais causas de aumentos de violência no âmbito familiar, isso se reflete principalmente por conta de grande parte das mulheres em situação de violência não ter dependência financeira e falta de emprego onde são obrigadas a depender da vontade do homem.

Um estudo realizado em Curitiba no período de 1993 a 2007 revelou que a violência física atingiu $57,97 \%$ dos casos avaliados seguida da violência psicológica em $16,96 \%$, as violências contra a mulher foram perpetradas por parceiros íntimos ${ }^{(11)}$. Outro estudo realizado em Brasília no ano de 2007 com 278 mulheres revelou que os socos e arremessos de objetos tiveram maior prevalência entre os atos de violência, ao mesmo tempo uma em cada 4 entrevistadas relataram ameaças ou lesões por arma branca ou de fogo ${ }^{(12)}$.

Em Minas Gerais, as mulheres vítimas de violência atendida nos serviços de saúde, 39,1\% das mulheres foram agredidas na face/pescoço o que ocasiona humilhação às vítimas por conta da exposição de sua imagem ${ }^{(13)}$.

O ex-conjuge é tido como o agressor por não aceitar o fim do relacionamento ou que a sua ex-companheira esteja tendo outro relacionamento, no entanto, em pesquisa na região metropolitana do Recife ${ }^{(14)}$, constatou-se que a maioria das mulheres foi agredida ou perderam suas vidas pelas mãos de seus companheiros, parceiros e cônjuges, além disso, a escolha da residência como local de ocorrência da violência se justifica pelo fato de ser um local em que as pessoas não vão interferir, além disso, o agressor conta com o medo e a vergonha da mulher em denunciá-lo.

Sendo um problema de saúde a violência traz desequilíbrios na qualidade de vida e no bem estar das mulheres vítimas de violência comprometendo as Necessidades Humanas Básicas as quais discutiremos a seguir.

Necessidades Humanas Básicas comprometidas de mulheres vítimas da violência atendidas na DEAM.

Quando perguntado as mulheres vítimas de violência sobre as possíveis alterações em seu sono e repouso, 54\% informaram que dormem e repousam de 5 a 7 horas ao dia como mostra a tabela 1.

A necessidade de sono e repouso se define como um estado de bem estar, isento de sentimentos de ansiedade ou de medo, sendo também a regeneração do processo do organismo. Quando uma pessoa tem essa necessidade alterada por algum motivo, inclusive pela violência, a mesma tende a ter sua energia diminuída e ocasionalmente depressão, ansiedade e medo ${ }^{(15)}$.

Tabela 1 - Horas de sono e repouso das mulheres vítimas de violência atendida na Delegacia Especializada de Atendimento a mulher no período de 1 de julho a 31 de dezembro de 2011, no município de Belém-Pa.

\begin{tabular}{ccc|}
\hline Horas de sono & $\mathbf{N}^{\circ}$ & $\%$ \\
\hline 1 a 2 & 23 & 7,67 \\
3 a 4 & 90 & 30,00 \\
\hline 5 a 7 & 162 & 54,00 \\
8 a 10 & 25 & 8,33 \\
Total & $\mathbf{3 0 0}$ & $\mathbf{1 0 0 , 0 0}$ \\
\hline
\end{tabular}

Fonte: DEAM, 2011

Observou-se durante a entrevista que $27,00 \%$ das mulheres apresentavam hematomas, $13,33 \%$ equimoses, $7,00 \%$ hematomas e equimoses. As marcas causadas por lesões afetaram a integridade cutânea mucosa, deixando marcas aparentes. Grande parte dos autores revela que a violência geralmente manifesta-se por meio da agressão física, ocasionado marcas evidentes na pele, em seguida para o cerceamento da liberdade individual da vítima expondo a vergonha e ao constrangimento.

A necessidade sensorial é um componente vital para o ser humano, responsável pela captação de informações sobre o ambiente, as principais são a percepção visual e auditiva. Foi evidenciado que a mulher vítima de violência apresenta alteração no estimulo de percepção dos órgãos.

Com relação às necessidades sexuais das mulheres vítimas de violência, 65\% referiram não sentir vontade de manter relações com seus companheiros. Em uma revisão da literatura constatou-se a partir de uma análise interpretativa, que $21,7 \%$ das mulheres entrevistadas negavam ter satisfação sexual ${ }^{(16)}$.

A necessidade sexual é um componente crítico e necessária ao bem-estar geral, a mulher cometida pela violência, principalmente a sexual enfrenta dificuldades em se relacionar sexualmente por conta de medos criados com a situação de violência.

Durante as entrevistas, 37,67\% das mulheres vítimas de violência apresentavam ansiedade, $29,33 \%$ estavam tristes e ansiosas, 4,67\% estavam tristes e chorosas (tabela 2). 
Tabela 2 - Avaliação da auto-estima das mulheres vitima de violência atendida na Delegacia Especializada de Atendimento a mulher no período de 1 de julho a 31 de dezembro de 2011 no município de Belém.

\begin{tabular}{|ccc|}
\hline Auto-estima & No & $\%$ \\
\hline Tristeza & 42 & 14,00 \\
\hline Choro & 3 & 1,00 \\
\hline Ansiedade & 113 & 37,67 \\
\hline Triste/Ansie. & 88 & 29,33 \\
\hline Triste/Choro & 14 & 4,67 \\
\hline Todas citadas & 27 & 9,00 \\
\hline Normal & 13 & 4,33 \\
\hline Total & 300 & 100,00 \\
\hline
\end{tabular}

Fonte: DEAM, 2011

A autoestima é um sentimento pessoal, caracterizado por um conceito dinâmico que envolve mudanças diferenciadas para cada individuo, o nível de auto-estima de uma pessoa influencia em fenômenos diversos, como a habilidade de uma pessoa em formar relacionamentos interpessoais ${ }^{(17)}$.

Das entrevistadas, $42,33 \%$ estavam despenteadas e desarrumadas, $31 \%$ estavam despenteadas, a perda da vontade do autocuidado afeta diretamente na auto-imagem refletindo pelo momento e sofrimento pela qual a mulher passa. As necessidades de estima expressam o desejo de alcançar uma auto-avaliação estável, sua satisfação conduz a sentimentos de autoconfiança, porém, a insatisfação dessas necessidades produz o sentimento de inferioridade ${ }^{(18)}$.

A necessidade de segurança emerge quando as necessidades fisiológicas tenham sido satisfeitas até certo ponto, sendo representado como uma ponte ou transição para necessidades de nível mais elevado. Se o individuo satisfez sua necessidade de segurança, surgem necessidades de amor e de pertencente a um grupo ${ }^{7}$. A aceitação de pessoas em grupos diz respeito à gregária, uma necessidade comum a todos os seres humanos ${ }^{18}$.

Mediante a violência essas necessidades sofrem alterações ocasionadas pela rejeição, das mulheres entrevistadas, $77 \%$ referiram insegurança por conta da violência.

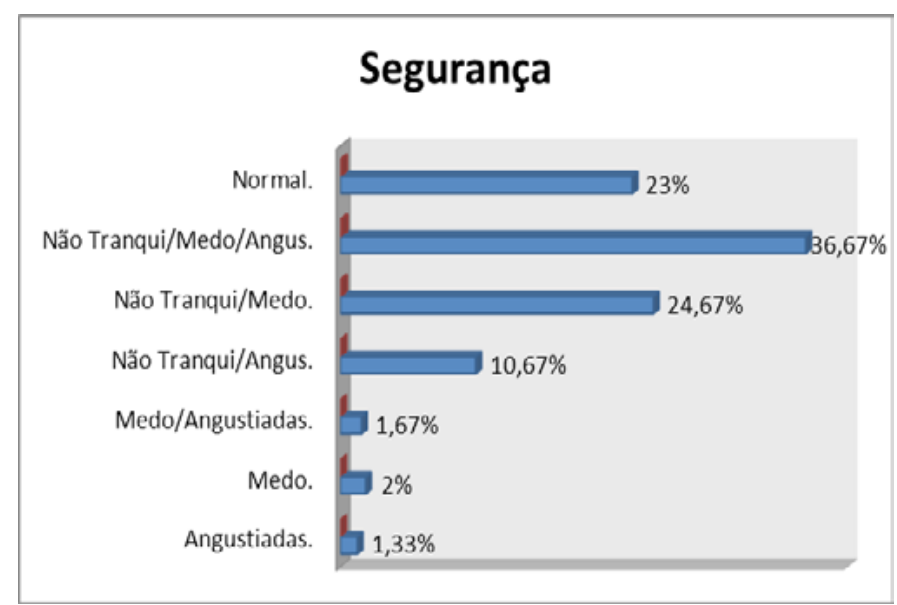

Figura 1 - Avaliação da segurança das mulheres vítimas de violência atendida na Delegacia Especializada de Atendimento a mulher no período de 1 de julho a 31 de dezembro de 2011, no município de Belém.

Com relação ao amor da mulher pelos parceiros, $86,33 \%$ das mulheres informaram não amar e nem se sentir amada pelo seu agressor, $9 \%$ disseram amar seu agressor e $4,67 \%$ amadas pelos parceiros. Quando perguntado a aceitação das mulheres na sociedade, $43 \%$ disseram ter sofrido pré-conceito por conta da violência sofrida. Quando as necessidades sociais não estão satisfeitas a uma resistência social, fazendo com que o ser se torne hostil com relação às pessoas que a cercam, conduzindo a uma solidão(19).

\section{CONCLUSÃO}

As mulheres vítimas de violência que buscaram atendimento na DEAM, estavam na faixa etária entre 26 a 30 anos, solteiras, sofreram agressão física e psicológica, foram agredidas na cabeça/face pelo seu ex-companheiro. As NHBs psicobiológicas e psicossociais das mulheres foram comprometidas pela violência como integridade cutânea mucosa, autoestima, autoimagem, gregária e a sexual.

$\mathrm{Na}$ atualidade o aumento da violência contra a mulher é um problema social e da saúde da mulher. As complicações desse evento fazem com que a violência contra a mulher seja observada como uma situação incomum.

Infelizmente esse contexto violento está presente em muitos cenários familiares, contribuindo para a construção de um fator geracional da violência que passa de pai para filho traduzindo assim a construção de uma geração violenta.

Como podemos observar nesse contexto a uma ausência de diálogo, postura exacerbada de dominação por parte do companheiro, exigência de obediência pela mulher, sem questionamento de suas necessidades e de seus direitos associado à falta de perspectivas de mudança, parece ser o fermento para práticas de violência psicológica e física.

Mediante esse problema de saúde pública, cabe a enfermagem a investigação, notificação e tratamento das necessidades humanas básicas comprometidas com a violência, pois os resultados mostram o comprometimento de todas.

Cuidar do ser humano em sua totalidade inclui elaborar e aplicar medidas de promoção e prevenção que podem ser potencializadas pela educação permanente, com esclarecimentos sobre os direitos e prerrogativas das vítimas. Sobretudo, assegurar que toda mulher, independente de classe, raça, etnia, religião, orientação sexual, renda, cultura, nível educacional, idade, goze dos direitos fundamentais e inerentes à pessoa humana. 


\section{AGRADECIMENTOS:}

A Dra. Alessandra do Socorro da Silva Jorge Diretora da Divisão Especializada de Atendimento à Mulher (DEAM) - Belém-Pará pelo apoio e colaboração na realização desse estudo.

As todas as mulheres que direta e indiretamente contribuíram que aceitaram participar do estudo com a finalidade reflexão e discussão da temática buscando ações para redução desse evento que traz conseqüência gravíssima para a mulher para a família e para a sociedade.

\section{Referências}

1. Santos MEA. Trabalho e violência em adolescentes estudantes: uma contribuição do enfermeiro. [Dissertação]. Rio de Janeiro: Universidade do Estado do Rio de Janeiro; 2009.

2. Gomes NP, Diniz NMF, Araujo AJS, Coelho TMF. Compreendendo a violência doméstica a partir das categorias gênero e geração. Acta Paul. Enferm.2007; 20(4):504-8.

3. Gomez NP, Diniz NMF. Homens desvelando as formas de violência. Acta. Paul. Enferm. 2008;21(2):262-67.

4. Lettiere A, Nakano MAS, Rodrigues DT. Violência contra a mulher: a visibilidade do problema para um grupo de profissionais de saúde. Rev. Esc. Enferm. USP. 2008; 42(3):467-73.

5. Ferraz MIR, Lacerda MR, Labronici LM, Maftum MA, Raimundo ML. O cuidado de enfermagem a vítima de violência doméstica. Congitare enferm. 2009;14(4):755-9

6. Horta WA. Processo de Enfermagem. São Paulo: EPU; 1979.

7.Lei $n^{\circ} 11.340$ de 7 de agosto de 2006 (BR). Cria mecanismos para coibir a violência doméstica e familiar contra a mulher e dá outras providências. Diário Oficial da União [ periódico na internet] Ago. 08, 2006.n 000001, Seção 1.

8. Gomez NP, Diniz NMF. Homens desvelando as formas de violência. Acta. Paul. Enferm. 2008;21(2):262-67.

9. Frank S, Coelho ES, Boing A. Perfil dos estudos sobre violência contra a mulher por parceiro íntimo: 2003 a 2007. Pan AM. J. public health. 2010;27(5):376-81.

10. Silva MA, Neto GHF, Figueroa JN, Filho EC. Violência Contra a Mulher: Prevalência e fatores associados a pacientes de um serviço público de saúde no nordeste brasileiro. Cad. Saúde Pública. 2010;26(2):264-72.
11. Labronici LM, Ferraz MIR, Trigueiro TH, Fegadoli D. Perfi da violência contra mulheres atendidas na Pousada de Maria 2010. Rev. Esc. Enferm. USP. 2010;44(1):126-133.

12. Moura LBA, Gandolfi L, Vasconcelos AMN, Pratesi R. Violências contra mulheres por parceiro íntimo em área urbana economicamente vulnerável, Brasília, DF . Rev. Saúde Pública.2009;43(6):944-53.

13. Garcia MV, Ribeiro LA, Jorge MT, Pereira GR, Resende AP. Caracterização dos casos de violência contra a mulher atendidos em três serviços na cidade de Uberlândia, Minas Gerais, Brasil.Rep. Public health.2008;24(11):2551-63.

14. Melo ZM, Silva DM, Caldas MT. Violência intrafamiliar: crimes contra a mulher na área metropolitana de Recife. Psico. Estud. 2009;14(1).

15. Potter PA. Perry AG. Fundamentos da enfermagem, $5^{\circ}$ Edição, Rio de Janeiro: Ed. Guanabara Koogan;2004.

16. Cruz, I CF. A sexualidade, a saúde reprodutiva e a violência contra a mulher negra: aspectos de interesse para assistência de enfermagem: [revisão]. Rev, Esc. Enferm. USP. 38(4)448457, dez 2004.

17. Sampaio, JR. O Maslow desconhecido: uma revisão de seus principais trabalhos sobre motivação. Rev. Adm., São Paulo, v.44, n.1, p.5-16, jan./fev./mar. 2009 [Disponível em] WWW. gerenciamento.ufba.br/disciplinna/lideram\%c3\%a7\%3\%20

18. Regis, LFLV. Porto, IS. A equipe de enfermagem e Maslow (IN)satisfações no trabalho. Rev. Brás. enferm; 59(4):565-568, jul.-ago. 2006. [Disponível em ] WWW.scielo/br/scieloss. php?script=sc 